\title{
Imaging of the Ischemic Penumbra in Acute Stroke
}

\author{
Deok Hee Lee, MD ${ }^{1}$ \\ Dong-Wha Kang, MD² \\ Jae Sung Ahn, MD ${ }^{3}$ \\ Choong Gon Choi, MD ${ }^{1}$ \\ Sang Joon Kim, MD ${ }^{1}$ \\ Dae Chul Suh, MD'
}

One of the main reasons for the soaring interest in acute ischemic stroke among radiologists is the advent of new magnetic resonance techniques such as diffusion-weighted imaging. This new modality has prompted us to seek a better understanding of the pathophysiologic mechanisms of cerebral ischemia/infarction. The ischemic penumbra is an important concept and tissue region because this is the target of various recanalization treatments during the acute phase of stroke. In this context, it is high time for a thorough review of the concept, especially from the imaging point of view.
Index terms:

Brain blood flow

Brain perfusion

Brain ischemia

Brain MR

Brain PET

Review

Korean J Radiol 2005;6:64-74

Received October 30, 2004; accepted after revision March 21, 2005.

Department of ${ }^{1}$ Radiology, ${ }^{2}$ Neurology, ${ }^{3}$ Neurosurgery, Asan Medical Center,

University of Ulsan College of Medicine

This work was partially supported by grants from the Korean Ministry of National Health and Welfare (03-PJ1PG1-CH06-0001).

Address reprint requests to: Deok Hee Lee, MD, Department of Radiology, Asan Medical Center, University of Ulsan College of Medicine, 388-1 Poongnap-2dong, Songpa-gu, Seoul 138-736, Korea. Tel. (822) 3010-4325 Fax. (822) 476-0090 e-mail: dhlee@amc.seoul.kr
$\mathrm{U}$

ntil now, recanalization treatment with using thrombolytics has been the only effective treatment for hyperacute ischemic stroke $(1,2)$. The procedure is usually done within three hours after the onset of symptoms for the intravenous method, and it's done within six hours for the intraarterial method. This quick intervention is based upon the hypothesis that there is a significant portion of tissue at risk of irreversible injury that could be recovered if swift reperfusion is within these time periods. The area that can be salvaged by timely reperfusion is referred to as the "ischemic penumbra." The aim of radiological imaging before recanalization treatment is to identify those patients who can most benefit from the treatment and to exclude those patients who are at a large degree of risk with using recanalization treatment. When considering this aim, it's very crucial to clarify the extent of the salvageable tissue and the ischemic core as quickly and accurately as possible.

There have been many laboratory-based and clinical functional studies that have analyzed the hemodynamic and pathophysiologic responses of the brain to ischemia, including xenon-computed tomography (Xe-CT), positron emission tomography (PET), and single photon emission computed tomography (SPECT). However, applying those modalities in clinical environments is nearly impossible due to a variety of reasons. Although it has some limitations, MR is the most convenient and reliable modality that is capable of providing valuable information on the extent of ischemic injury and the perfusion status, together with supplying the morphological information. Advances in recent CT technology, such as multi-detector row CT (MDCT), has enabled physicians to identify the vascular and perfusion status within an amazingly short imaging time.

In this context, a thorough understanding of the recently expanded knowledge concerning the acute ischemic process is mandatory for the proper use of these modalities. The purposes of this essay are to thoroughly review the concept of the ischemic penumbra and to explore its imaging findings when using the different modalities. 


\section{Pathophysiology of Brain Ischemia and the Ischemic Penumbra}

To better understand the ischemic penumbra, it is worthwhile to review the pathophysiologic mechanism of ischemic brain damage. Reviewing the "four tissue compartments concept" is a very good strategy for understanding the ischemic process (Fig. 1). The compartments can be distinguished by the various physiological imaging modalities during acute ischemic stroke: 1 ) the unaffected tissue; 2) the mildly hypoperfused tissue, but this is not usually at risk (the oligemic tissue); 3) the tissue at risk (the ischemic penumbra); and 4) the tissue already irreversibly damaged (the ischemic core) (3). We may have obtained the rough parameters of regional cerebral blood flow $(\mathrm{CBF})$ by virtue of a variety of experiments $(3-9)$.

The regional $\mathrm{CBF}$ of the unaffected normal brain tissue is about $50-60 \mathrm{ml} / 100 \mathrm{~g} / \mathrm{min}$. This tissue compartment without any perfusion abnormality corresponds to Area 1 of Figure 2 (10). The first response of the brain tissue to the decrease of the cerebral perfusion pressure (CPP) is to dilate the vessels in the involved territory. The regional cerebral blood volume (CBV) will increase via the increased vascular spaces to maintain the CBF. This mechanism is called "autoregulation" and this represents the "hemodynamic reserve" of the tissue. This autoregulatory function will remain intact if the decrease of CPP is in the range of $60-130 \mathrm{mmHg}$, which is within the range of the mean blood pressure. This tissue compartment that is under perfect autoregulation corresponds to Area 1' of Figure 2. Both Areas 1 and 1' comprise the unaffected compartment that maintains an adequate level of CBF. Although it is not sufficient, this autoregulatory mechanism will continue throughout the ischemic process until the brain tissue is irreversibly damaged.

Below the threshold, the tissue area becomes "oligemic," and this is characterized by decreased tissue perfusion without any functional or morphological impairment. This tissue shows moderately reduced $\mathrm{CBF}$, an increased oxygen extraction fraction (OEF), and a normal cerebral metabolic rate of oxygen $\left(\mathrm{CMRO}_{2}\right)$. This benign oligemia tissue compartment corresponds to Area 2 of Figure 2. This mechanism of maintaining the $\mathrm{CMRO}_{2}$ by the augmentation of the $\mathrm{OEF}$ is referred to as the "perfusion reserve." The brain tissue in this tissue compartment will maintain its function and cellular integrity, notwithstanding a significant decrease of the CPP owing to the compensatory mechanism. The oligemic tissue usually surrounds the ischemic core and the penumbra tissue, and it generally reveals a favorable tissue outcome even without prompt recanalization. This area is usually not a target for acute recanalization treatment $(6,11)$. The rough $\mathrm{CBF}$ threshold of oligemia and the ischemic penumbra is about $18-20$ $\mathrm{ml} / 100 \mathrm{~g} / \mathrm{min}$ (about $30-40 \%$ of normal, the penumbral threshold).

If the CPP decreases further, an increase of the $\mathrm{OEF}$ is also insufficient to maintain the $\mathrm{CMRO}_{2}$ with the exhaustion of the perfusion reserve, and this results in metabolic impairment and neuronal shutdown. The imaging hallmark of this compartment is a mildly decreased $\mathrm{CMRO}_{2}$, while the OEF is markedly increased. This tissue compartment of an impending infarction, the ischemic penumbra, corresponds to Area 3 of Figure 2. The tissue may maintain its cellular integrity even though it is already suffering from profound metabolic impairment. It may persist in this state until the CBF decreases below $10-12 \mathrm{ml} / 100 \mathrm{~g} / \mathrm{min}$ (below $20 \%$ of normal, the infarction threshold). This area can also be found as late as $30-48$ hours after the onset of symptoms (12). The definition and pathophysiologic characteristics of this compartment will be discussed in detail later in this section.

With the progression of perfusion failure, the penumbra zone eventually undergoes irreversible ischemic damage. This tissue can be characterized as an area of markedly decreased $\mathrm{CMRO}_{2}$. In this area, the values of the $\mathrm{CBF}$, $\mathrm{CBV}$ and $\mathrm{OEF}$ can be variable (6). This tissue compartment of the ischemic core corresponds to Area 4 of Figure 2.

Although the perfusion thresholds have been quickly summarized here in a very simple manner, one should

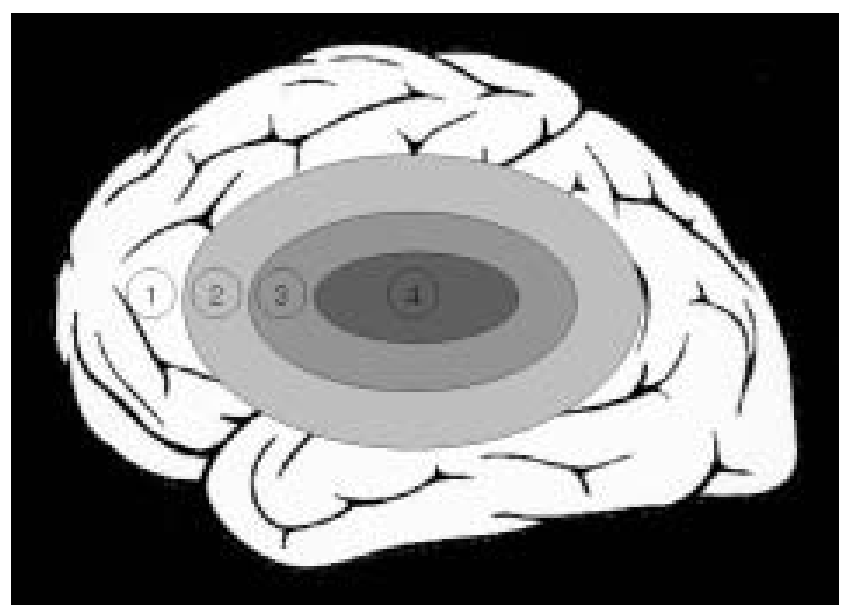

Fig. 1. A schema of the concentric, four-compartment, brain ischemia model. The brain parenchyma affected by hypoperfusion can be compartmentalized by using various physiologic imaging modalities. The ischemic core (4) represents a tissue compartment that is irreversibly damaged or infracted, and it is surrounded, to a various extent, by the ischemic penumbra (3) that is at risk of infarction. Between the unaffected area (1) and the ischemic penumbra, there is an area of benign oligemia (2) that usually survives the ischemic insult, even without prompt reperfusion. The extent of each compartment changes with the passage of time after the initiation of hypoperfusion. 
keep in mind that we have presented only rough values and the real values cannot be easily obtained from any single physiological or hemodynamic imaging modality. All of these phenomena constitute a dynamic ongoing process that shows a variety of changes according to the duration and the severity of the hypoperfusion. The tissue's tolerance to ischemic damage is also dependent on the residual flow and the duration of the flow disturbance (7).

Etymologically, the term 'penumbra' originates from Latin: paeane (almost) + umbra (shadow), meaning a gray zone between the complete shadow (i.e., the ischemic core) and the complete illumination (i.e., the normal or benign oligemia) that can be seen during a partial solar

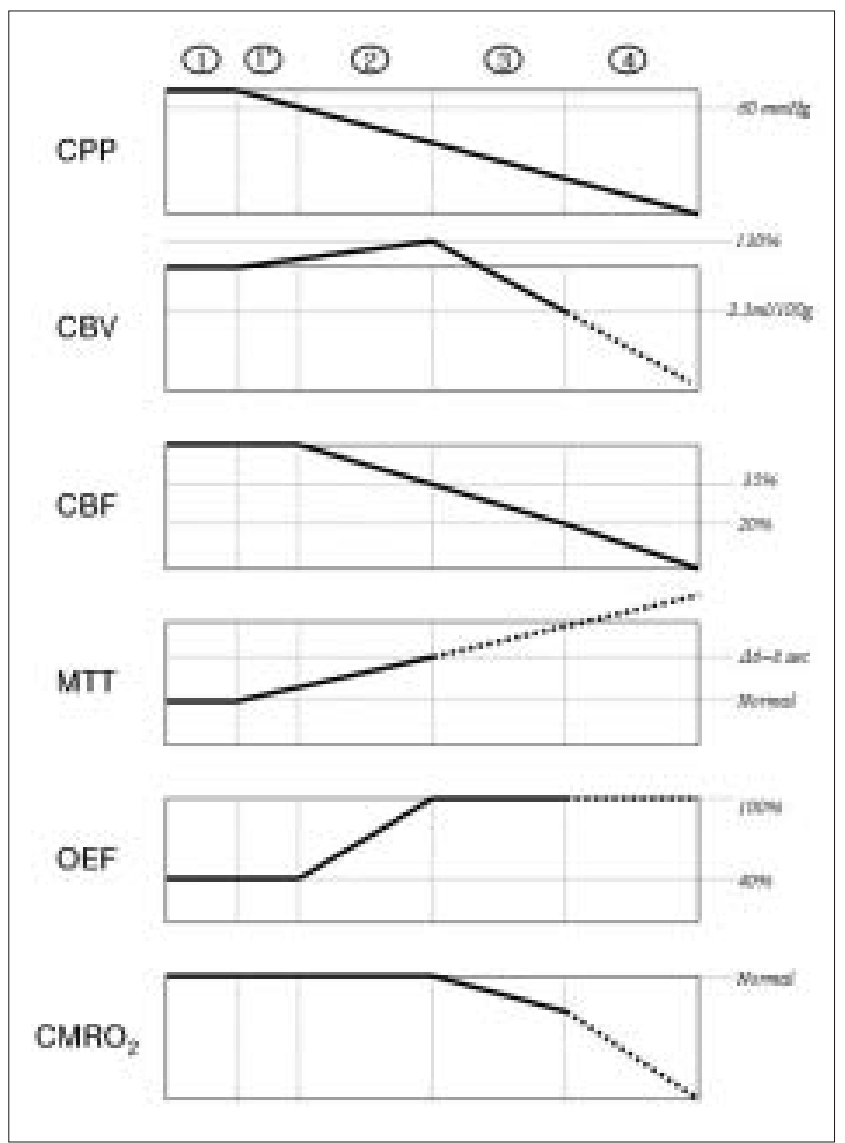

Fig. 2. Schematic graphs representing the dynamic change of the various hemodynamic or metabolic parameters during the ischemic process of the brain. Each $y$ axis represents the level of those parameters. The $x$ axis is divided into four areas, $1-4$, according to the four-compartment concept. Area 1 is the unaffected area ( $1^{\prime}$ is autoregulated), Area 2 is the benign oligemia, Area 3 is the ischemic penumbra and Area 4 is the ischemic core. Rough thresholds are presented at the left side of each graph to help understand those parameters. The reader should refer to the text for the detailed thresholds. If the values are variable, then thick, dotted curves are used. CPP $=$ cerebral perfusion pressure; $\mathrm{CBV}=$ cerebral blood volume; $\mathrm{CBF}=$ cerebral blood flow; MTT = mean transit time; OEF = oxygen extraction fraction; and $\mathrm{CMRO}_{2}=$ cerebral metabolic rate of oxygen. eclipse. In 1981, Astrup et al. (4) first coined the term "ischemic penumbra" to represent a certain area of brain tissue that is perfused at a level between the thresholds of functional impairment and morphologic integrity, and this area has the capacity to recover if perfusion is restored in a timely fashion. In other words, if the tissue is not reperfused, it will undergo irreversible changes over time. In that sense, "ischemic penumbra" and "tissue at risk" are interchangeable terms.

The major concern during the initial hemodynamic evaluation of the acute ischemic patient is the viability of the penumbra zone. The degree of perfusion abnormality and the duration of the ischemia should be considered when predicting the fate of the total lesion. However, in clinical settings, predicting the viability of the penumbra zone is a complex task. Warach proposed "The 4-factor model" for this purpose (13). The model consisted of a time factor, a hemodynamic factor, a tissue factor and an intervention factor. There is no absolute viability threshold that is independent of time, and there is no absolute time window for the tissue viability.

\section{Conventional CT}

Conventional non-enhanced CT has played a major role in the imaging of acute stroke due to its wide availability, its simplicity and its ability to provide strong clinical evidence (14). Early CT hypodensity that is noted within six hours of symptom onset is tissue that is doomed to irreversible infarction. Furthermore, the conventional CT alone cannot distinguish what tissue is at risk (15). The major role of this unenhanced $\mathrm{CT}$ in the acute setting is to exclude the hemorrhagic lesions and major infarctions.

\section{Multidetector CT}

Things have changed with the advent of $\mathrm{CT}$ perfusion (CTP) and CT angiography (CTA), and both of these imagings can easily be acquired using novel MDCT techniques. CT angiography is a very good tool to evaluate the vascular status of the neck and the intracranial vessels. If one recognizes the potential pitfalls of this technique, such as problems with the skull base or the densely calcified plaque, it can be very useful for performing a rapid evaluation.

With the current CTP method, the dynamic perfusion status of the brain can be evaluated in a $0.5 \mathrm{sec}$ time resolution and it can cover with a $20-30 \mathrm{~mm}$ slice thickness at a time. We can get each time-density curve on a pixel-by-pixel basis. Using these curves, several parameter maps can be reproduced, such as the time-to-peak 
(TTP) map, the mean transit time (MTT) map, the CBF map and the CBV map. It is believed that CTP is capable of providing quantitative data on both the $\mathrm{CBF}$ and the CBV, unlike the current MR perfusion techniques (16). However, any absolute values are still unreliable due to various reasons. Although it has been mentioned that the severity of the ischemic process can not be judged by the perfusion parameters alone, it would be quite helpful to have some simplified perfusion values for interpretation with using the rough $\mathrm{CBF}$ threshold values that are given above. Again, we should keep in mind that there is an obvious gray zone between the tissue at risk and the tissue with irreversible injury.

Several studies have reported that the sensitivity of color-displayed perfusion maps for the territorial ischemia was over $90 \%(14,17)$. We can easily obtain information regarding the extent of the perfusion abnormality and the relative value of the parameters with these maps. Among them, the time parameters on the maps such as TTP and MTT maps are very sensitive to the hemodynamic abnormality. Both the CBF and CBV maps are helpful to predict the outcome of an ischemic lesion (Fig. 3). We can

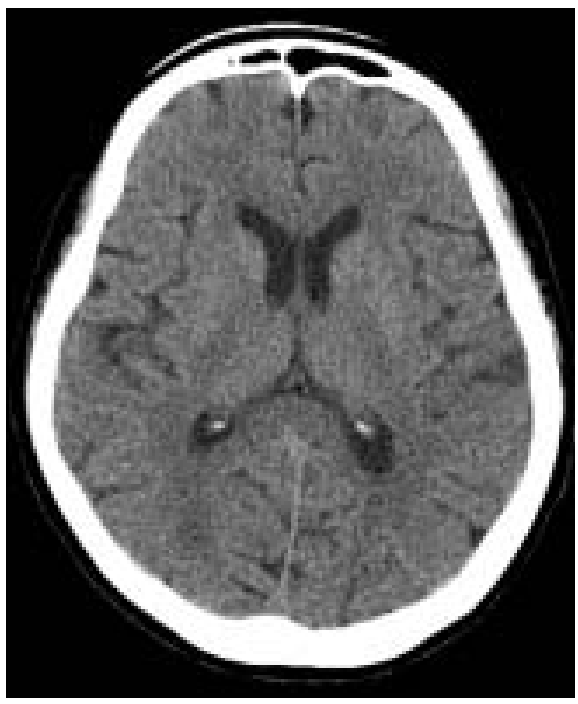

A

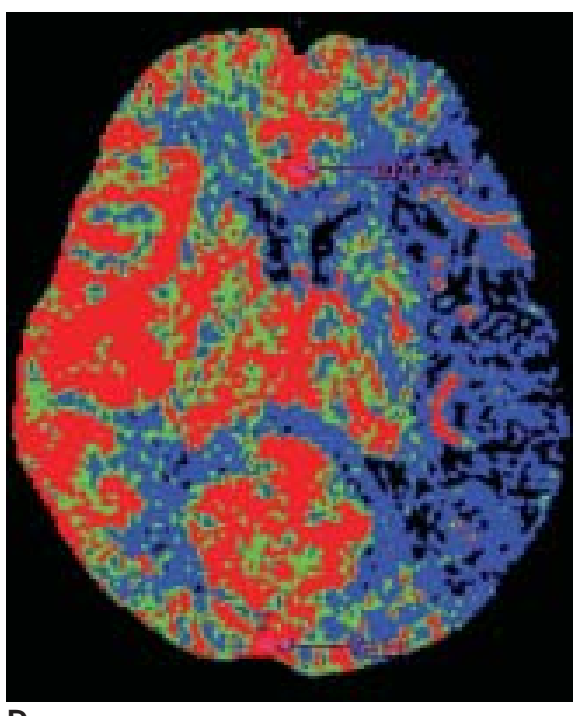

D
B

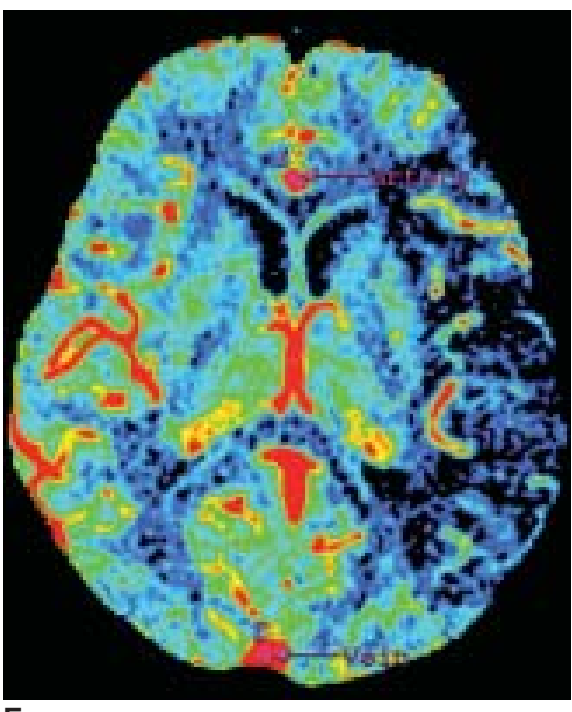

E

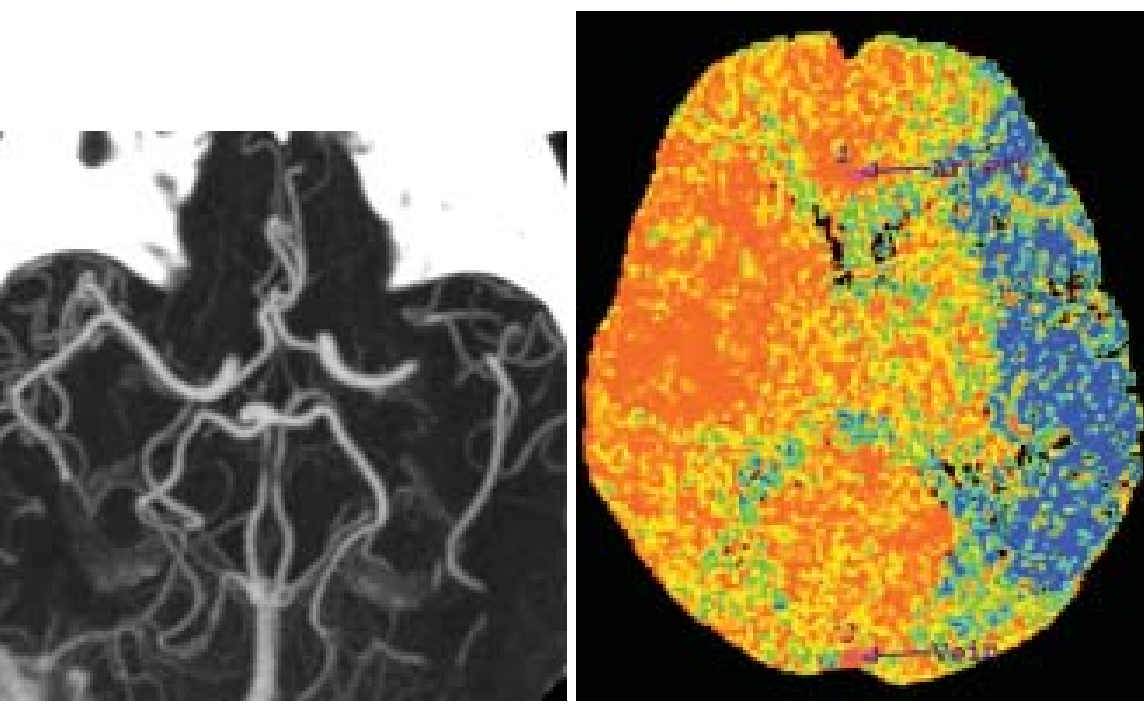

C

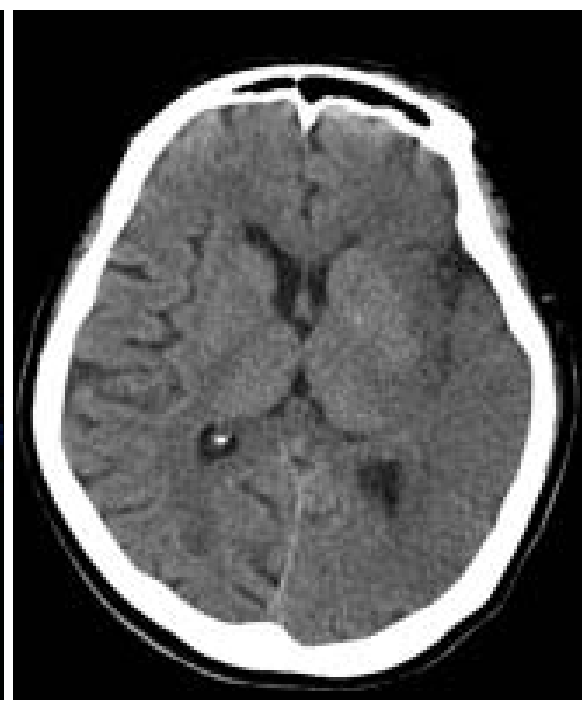

$\mathbf{F}$

Fig. 3. The initial non-enhanced CT (A), the CT angiography (B), and the CT perfusion maps (C-E) were obtained about one hour after symptom onset in a 63-year-old female patient who presented with right side weakness. Her initial national institutes of health stroke scale score was eight. There is no definable early CT sign on the initial CT scan (A) although a long segment occlusion of the left distal middle cerebral trunk is noted on the slap maximal intensity projection image of CT angiography (B). A large perfusion defect is found in the entire left middle cerebral trunk territory on the mean transit time (C), CBV (D), and CBF (E) maps. On the follow-up CT (F) obtained about 24 hours after the initial imaging, an obvious low density infarction is noted at the area of the initial perfusion abnormality. 
roughly assume that a brain area without any density change on non-enhanced $\mathrm{CT}$ is tissue at risk when both the $\mathrm{CBF}$ and $\mathrm{CBV}$ are decreased. A good tissue outcome is predictable if a tissue area reveals a normal or elevated $\mathrm{CBV}$, even though the time and CBF maps show abnormality. On the contrary, if both the $\mathrm{CBF}$ and $\mathrm{CBV}$ are severely reduced or not measurable, the tissue area is usually irreversibly injured. A study recently evaluated value thresholds $(18,19)$, in which a relative $\mathrm{CBF}$ value of $66 \%$ was used as a threshold of normal autoregulation. If the value of a lesion is lower than that, then it is ischemic. A CBV threshold of $2.5 \mathrm{ml} / 100 \mathrm{~g}$ was then applied to discriminate between the ischemic core and the penumbra.

\section{Conventional MR}

Conventional MR imaging is quite insensitive to the early ischemic change (20). It is nearly impossible to see any change on the T1- or T2-weighted images (WI) within several hours after symptom onset. In the earlier periods of MR research, there were reports on the superiority of MR over CT within 24 hours of symptom onset (21). However, MR appeared to be less sensitive than non-enhanced CT when it comes to lesions that are still within six hours of symptom onset (16).

There have been recent reports regarding the usefulness of fluid-attenuated inversion recovery (FLAIR) images during the acute phase of infarction $(22,23)$. By eliminating the cerebrospinal fluid signal surrounding the ischemic cortices, the FLAIR images are more sensitive to ischemic change than any of the other conventional pulse sequences. Furthermore, the collateral cortical flow may be seen as high signal vascular structures due to slow flow enhancement (Fig. 4). A recent study has reported that the ischemic penumbra could be visualized as the area of intravascular signal surrounding the high signal lesion on the diffusion weighted image (DWI) (23).

\section{Diffusion Weighted Imaging}

In the animal stroke models, the DWI changes were noted within a few minutes after arterial occlusion. The flow threshold for the significant decrease of the relative apparent diffusion coefficient ( $\mathrm{rADC} ; 0.5-0.8$ ) is within the $15-20 \mathrm{ml} / 100 \mathrm{~g} / \mathrm{min}$ range (24). The degree of the apparent diffusion coefficient (ADC) reduction depends on both the anatomic location and the duration of ischemia. It was believed that once the DWI or ADC lesions appeared, especially in humans, infarction almost always occured in the involved tissue (25). However, there have been several clinical reports regarding the reversibility of DWI lesions and this reversibility has also been well demonstrated in the animal models (26-28).

Although the reversibility of the DWI lesion is rather limited, some portion of the lesion can be reversed by reperfusion (Fig. 5). Fiehler et al. have recently suggested that severe decreases of the ADC values do not always predict irreversible tissue damage $(29,30)$. They concluded by stating that the severity and duration of the ischemia were more important factors than the absolute value of the $\mathrm{ADC}$ for the normalization of this value by the reperfusion. In addition to that, they observed a $19.7 \%$ frequency of normalization by their own definition. They believed that there were some portions of "tissue at risk" even within the brain tissue having an initially decreased ADC value. They suggested the possibility of widening the MR

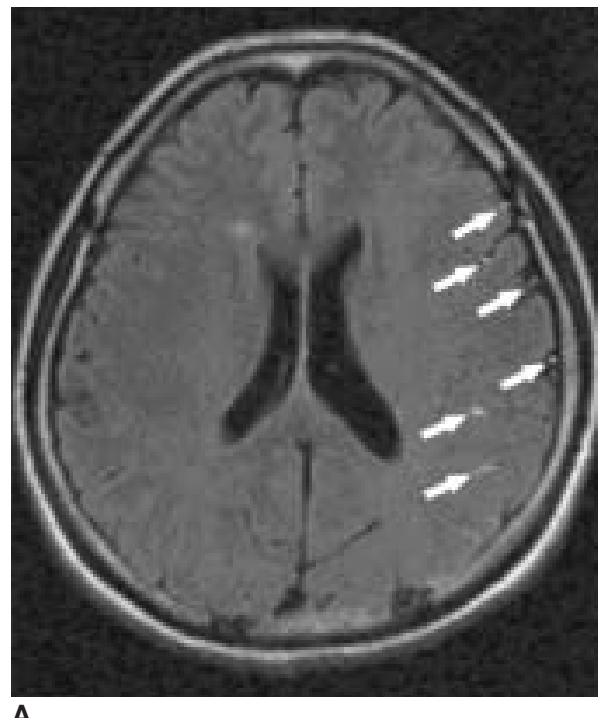

A

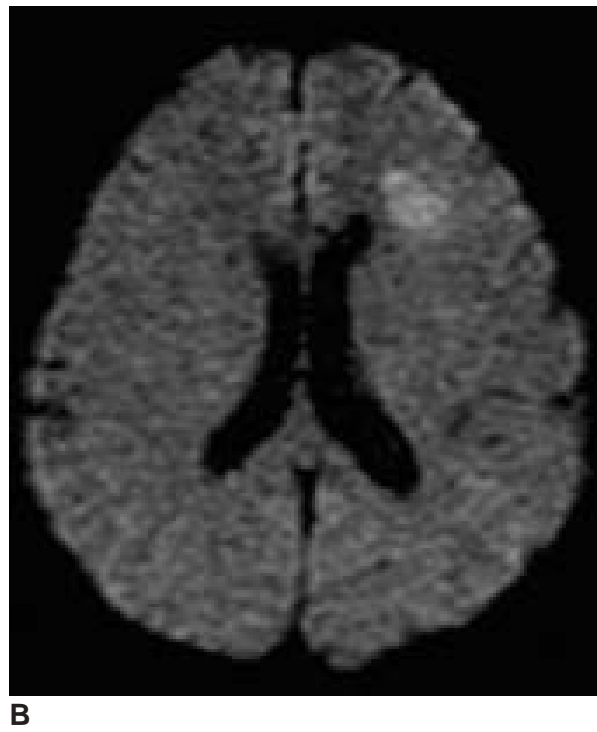

Fig. 4. The fluid-attenuated inversion recovery image $(\mathbf{A})$ and its corresponding DWI with a b-factor of $1000 \mathrm{sec} / \mathrm{mm}^{2}$ (B) that were obtained during the acute phase. We can assume the diffusion weighted image high signal lesion is the core of the ischemia, and the surrounding parenchyma encompassed with the intravascular high signals (arrows) related with the slow flow is the hypoperfused area. Although the area may contain the ischemic penumbra and the benign oligemia, this area can be the target of prompt recanalization treatment. 
indications for thrombolytic treatment to include those patients without a diffusion-perfusion mismatch if the patient presented within three hours of the symptom onset.

\section{Perfusion Weighted Imaging}

At the present, the dynamic susceptibility-weighted perfusion imaging using gadolinium contrast media is the standard technique for MR perfusion study. The basic technical aspects of perfusion-weighted image (PWI) are given in a previous review (31). When the ischemia occurs, there is less signal loss and/or delayed time to the peak signals with this technique in the affected territory (32).

The CBV, as measured by both PET and MR, is widely known to be relatively nonspecific. The cortex in an occluded arterial territory may have a increased CBV that is initially due to the compensatory vasodilatation that occurs until the collateral circulation becomes insufficient (33). Other parameters can be used (Fig. 6) (34). Butcher et al. (35) have identified the threshold values of the perfusion parameters. They found that the average delay in the MTT was 8.3 seconds in the infarcted tissue and 6.5 seconds in the salvaged tissue; the acute $\mathrm{CBF}$ was $10 \%$ lower in the infarcted $(56 \%)$ regions relative to the salvaged $(66 \%)$ regions, and the acute $\mathrm{CBV}$ was increased in all affected hemispheres without there being any differences between the infarcted and salvaged regions. There have been several other similar studies on the perfusion parameter thresholds, but the results have been inconsistent, mainly because it is very difficult to control the

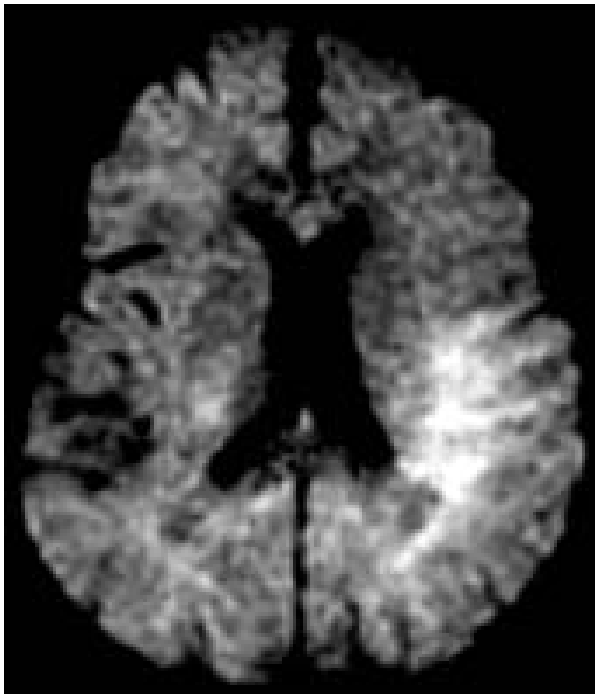

A

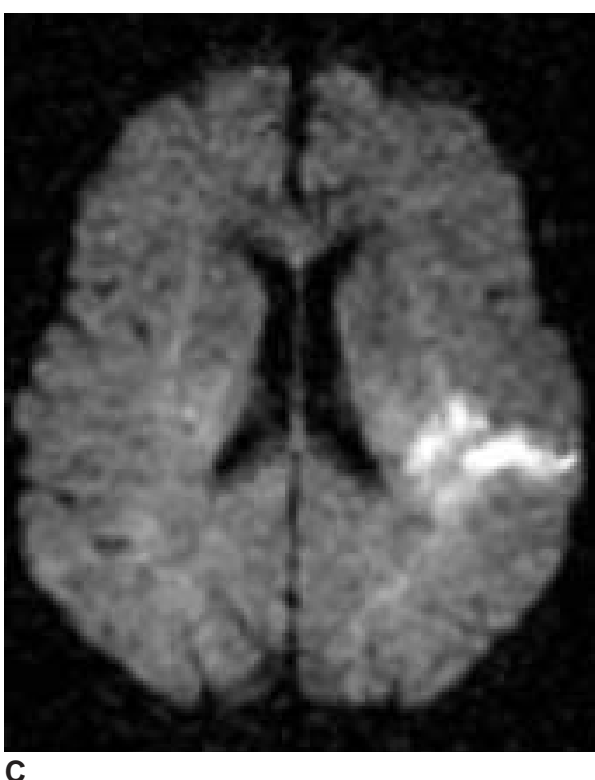

C

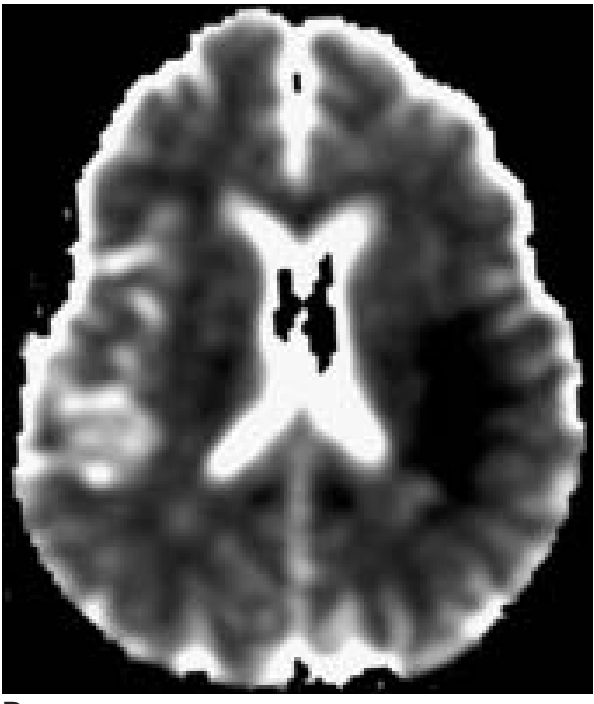

B

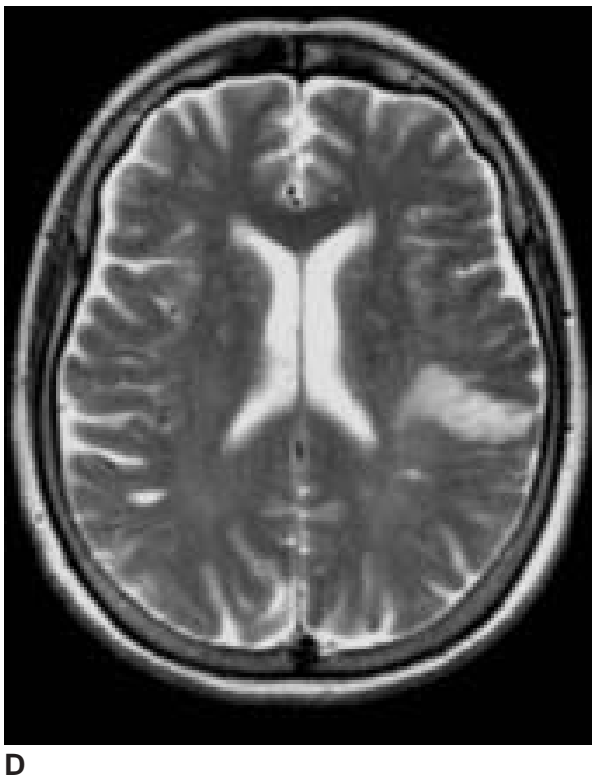

Fig. 5. The diffusion weighted image (A) and apparent diffusion coefficient map (B) obtained 2 hours after symptom onset in a 70-year-old female who presented with aphasia and right-side weakness. The relative apparent diffusion coefficient of the lesion was about 0.8 . She responded to the intravenous thrombolytic treatment that was initiated immediately after MR imaging. The follow-up diffusion weighted image (C) and T2-weighted images (D) show the decrease extent of the initial diffusion weighted image lesion. The difference in the extent of the high signal lesion between the initial diffusion weighted image and the followup T2-weighted image can be interpreted and treated as the ischemic penumbra, which would progress to infarction if we failed to perform timely recanalization. 
reperfusion and time factors. As a practical matter, we do not recommend strict application of the threshold values at this time. Most centers generally use a qualitative analysis of the most sensitive time map to evaluate the extent of the perfusion abnormality, while other parameter maps are being used as ancillary information for predicting the fate of the hypoperfused area (36).

\section{Diffusion Weighted Imaging-Perfusion Weighted Imaging Mismatch}

To simplify the MR definition of the penumbra, which has been previously defined as the mismatch between the diffusion and perfusion abnormalities (37), we will consider the DWI and PWI together. A significant mismatch has been operationally defined as "at least a $20 \%$ discrepancy between the smaller DWI lesion and the larger PWI lesion in their volume" (9). This study suggests that enlargement of the area of infarction was likely to occur if the area of perfusion deficit was larger than the area of the initial diffusion abnormality, and this mismatch may represent the ischemic penumbra (Fig. 7) (37). As mentioned in our previous section, the sensitive time maps such as the MTT or TTP are usually preferred to estimate the area of the perfusion abnormality.

It has recently been suggested that the mismatch probably overestimates the penumbra (Fig. 8) (34). Comparison of perfusion parameters to the contralateral hemisphere is, perhaps, the easiest way to interpret the perfusion parameters, yet it remains debatable as to what

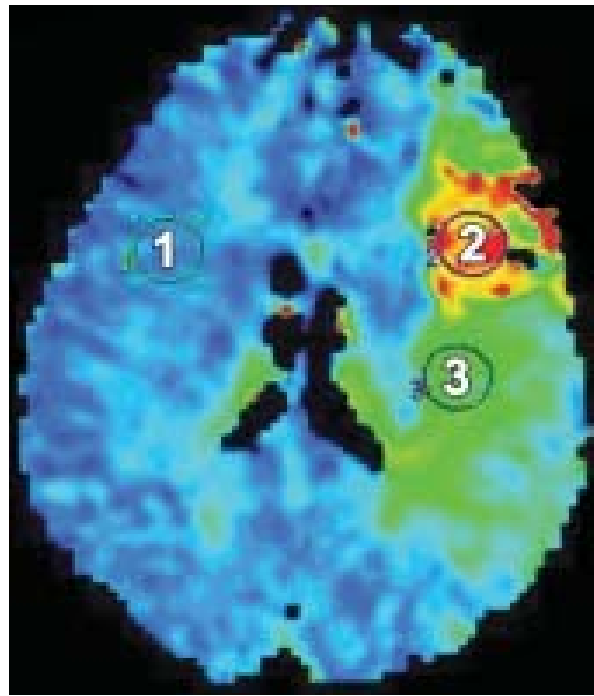

A

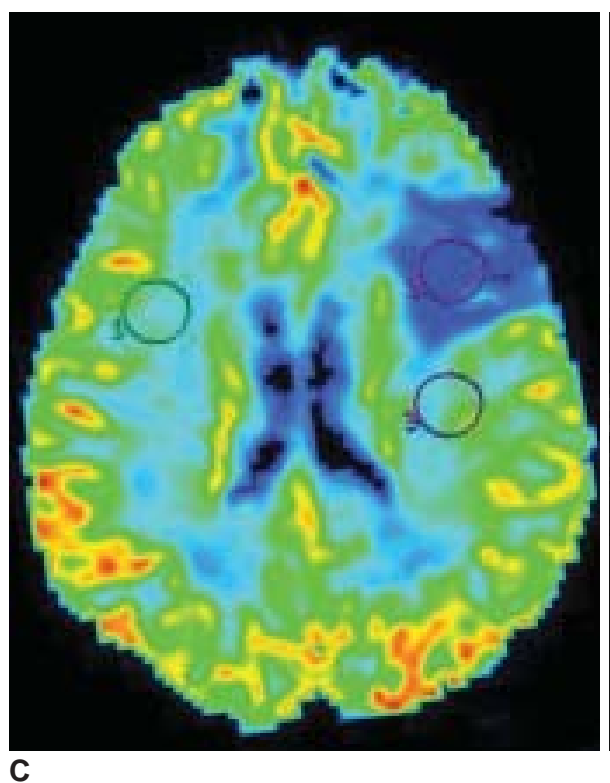

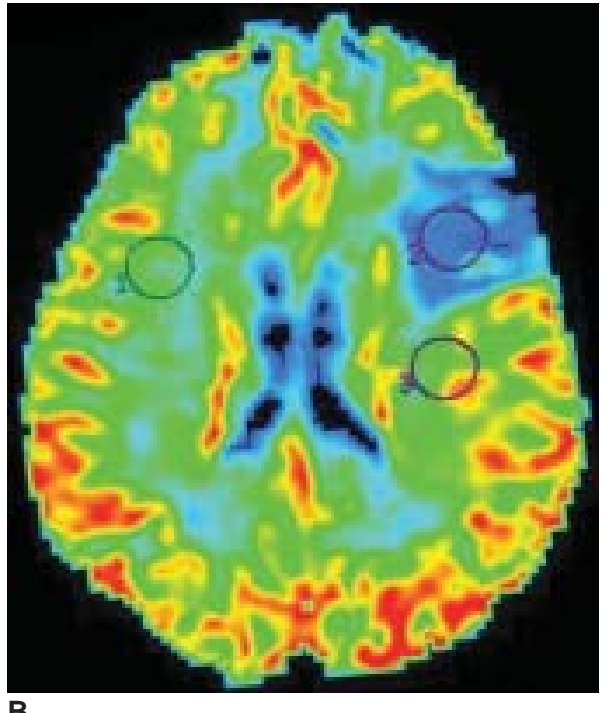

B

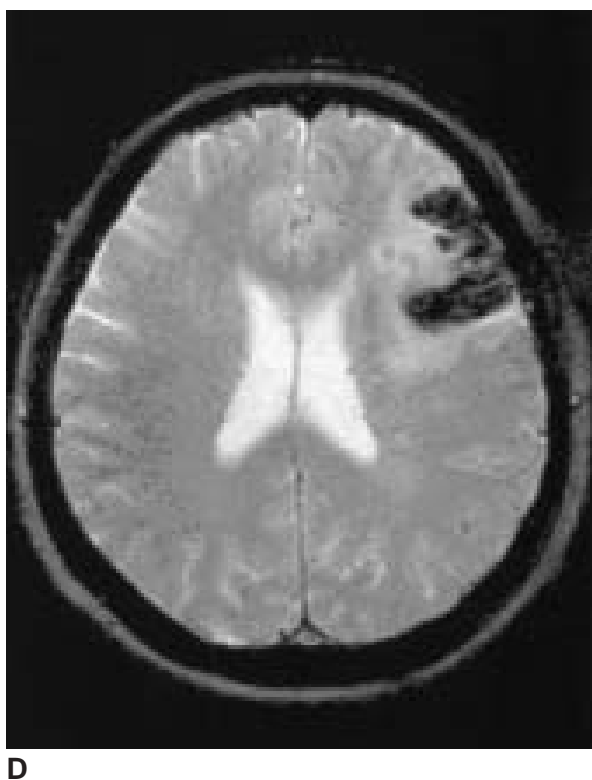

Fig. 6. The MR perfusion maps obtained three hours after symptom onset in a 72-year-old female with global aphasia and right-side weakness. The mean transit time map $(\mathbf{A})$ is regarded as the most sensitive map for perfusion abnormalities while the other maps, such as the cerebral blood volume map (B) and the cerebral blood flow map (C), provide other ancillary information. Area 1 represents normal perfusion status and it has no risk of infarction. Area 2 shows the marked prolongation of the mean transit time with the concomitant decrease of both the cerebral blood volume and cerebral blood flow. This area usually has no chance to survive from infarction. This area eventually showed hemorrhagic infarction on the follow-up gradient echo image (D). Area 3 of moderately prolonged mean transit time shows a slightly increased cerebral blood volume value to maintain the cerebral blood flow. This area often has a benign course and it is salvageable via recanalization treatment. 


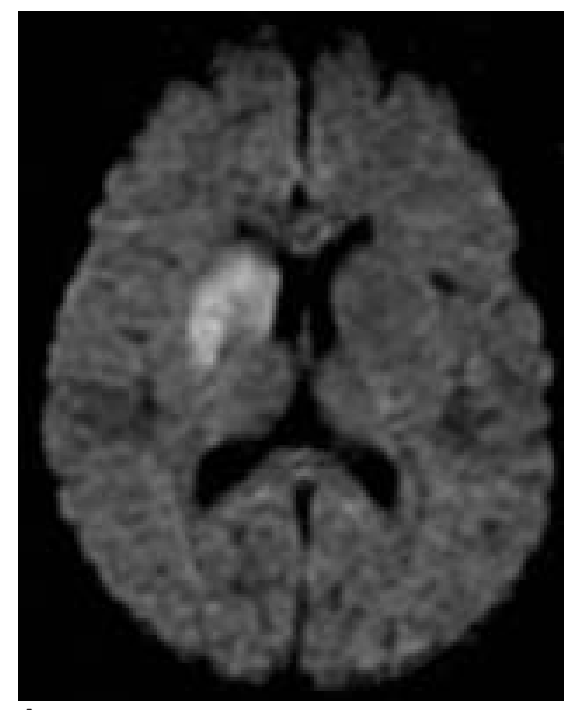

A

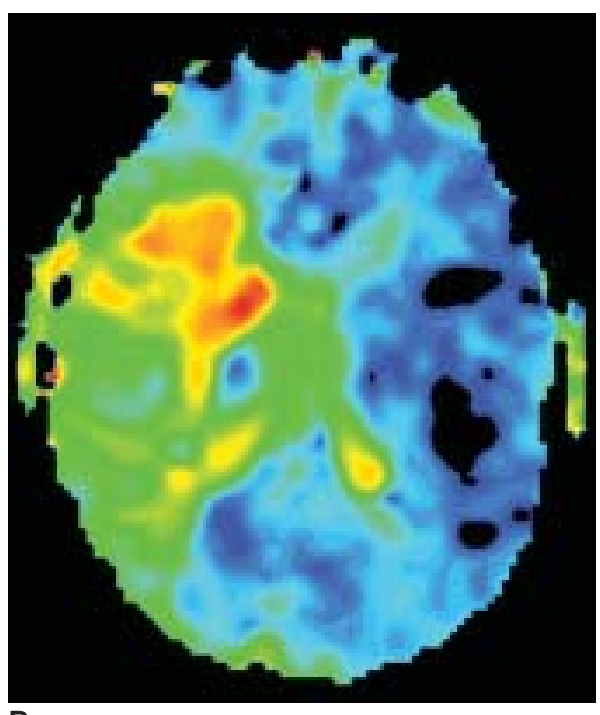

B

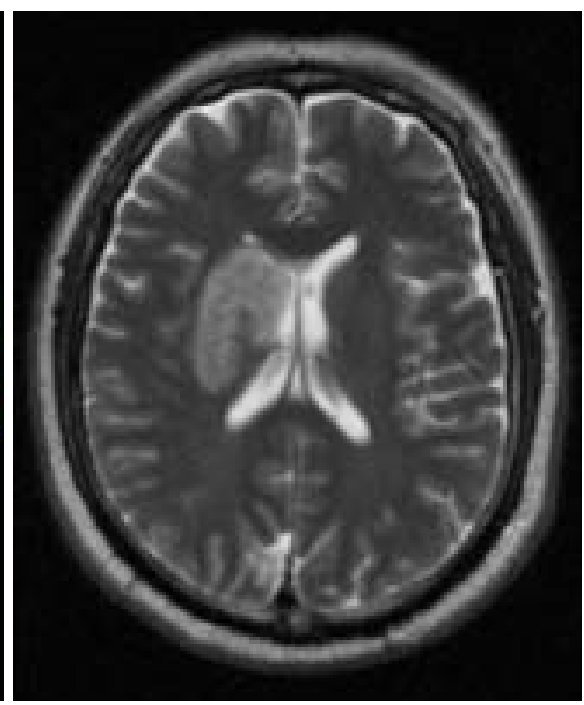

C

Fig. 7. The diffusion-weighted maps $(\mathbf{A})$ and mean transit time map $(\mathbf{B})$ of a 59-year-old male presenting with left-side weakness two hours prior to imaging. The area of perfusion abnormality is much larger than the area of the high signal lesion on the diffusion weighted image. The mismatched area can be operationally regarded as the ischemic penumbra. Intravenous thrombolytic treatment was initiated after the imaging. A follow-up T2-weighted image (C) obtained five days later shows mild progression of the lesion, but there is sparing of most of the initial penumbra zone.

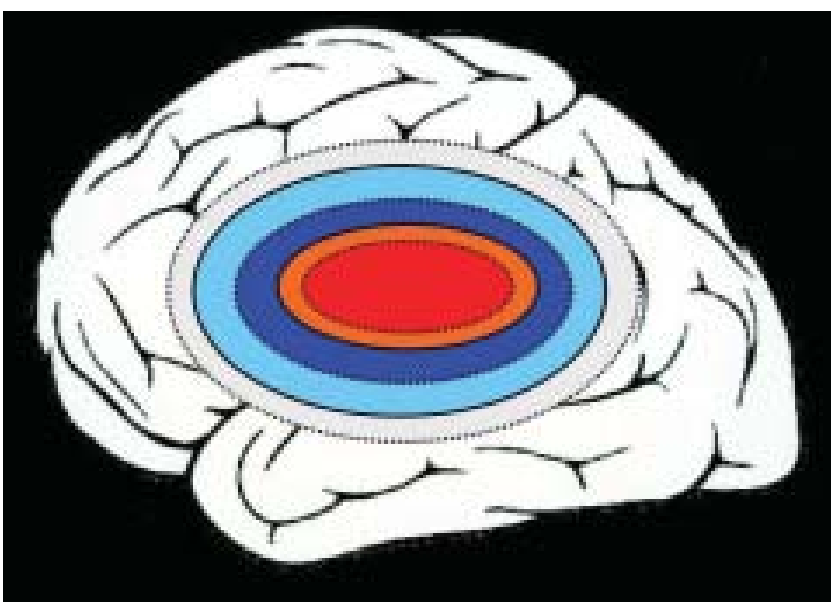

Fig. 8. A modified diagram of the concentric, four-compartment brain ischemia model. The diffusion weighted image lesion extent (orange) is usually larger than that of the ischemic core (red). The perfusion weiguted image lesion extent (light blue) is usually larger than that of the ischemic penumbra (blue).

extent these methods may allow the distinction between reversible and irreversible ischemia (38).

\section{MR Spectroscopy}

Proton MR spectroscopy (MRS) can measure several brain metabolites (39), including $N$-acetylaspartate (NAA) and lactate, and these are important metabolites during ischemic stroke $(40,41) . N$-acetylaspartate is a neuronal marker that decreases steadily to $50 \%$ of the baseline value six hours after symptom onset. Lactate is a product of anaerobic glycolysis and it rises once the CBF decreases below $20 \mathrm{ml} / 100 \mathrm{~g} / \mathrm{min}$, which is the threshold at which electrical activity ceases; this occurs within 10 minutes. By combining these findings, the tissue at-risk can be defined as an area with an elevation of lactate without any significant decrease for the NAA (42). Chemical shift imaging (CSI) was recently developed to provide distribution maps of the specific metabolites. This enabled us to spatially compare a DWI lesion with the distribution of the specific metabolites (43).

\section{Other Emerging MR Techniques}

Newer MR techniques has recently been developed and tried out. It is a well-known fact that hypoperfusion can cause the reduction of the $\mathrm{T} 2$ signals due to the increases in the deoxyhemoglobin concentration that are undetectable with conventional MR magnets. Such detection becomes possible with the advent of more powerful magnetic field machines (31). Grohn et al. have described three types of regions at risk of infarction using the 9.4T machines: 1 ) areas with a reduced $\mathrm{T} 2$ value and a normal $\mathrm{ADC}$ value, corresponding to hypoperfusion without ischemia; 2) areas with both reduced $\mathrm{T} 2$ and $\mathrm{ADC}$ values, corresponding to early hypoperfusion with ischemia; and 3) areas with increased $\mathrm{T} 2$ and reduced $\mathrm{ADC}$ values, corresponding to irreversible ischemia (44).

Experimental data suggest that endogenous blood 
oxygen level dependent (BOLD) contrast analysis may improve the assessment of tissue viability (45). The ratio of oxyhemoglobin to deoxyhemoglobin, as measured by MR in the capillary and venous compartments, reflects the OEF (46) and $\mathrm{CMRO}_{2}$ (47). A decreased signal intensity on the gradient-recalled echo-planar T2*-weighted MR was noted shortly after the vascular occlusion. In a rat model, the area of susceptibility-related signal intensity extended beyond that of the decreased diffusion (48). The OEFrelated signal changes were detected in the early minutes of ischemia and during moderate hypoperfusion in the penumbra-like tissue (45).

\section{Positron Emission Tomography}

As mentioned previously, PET is a very useful tool for evaluating the perfusion status of specific brain tissue, including the hemodynamic and perfusion reserves $(3,6,7$, $49,50)$. Without PET, we would not have had all of the available ideas and information being reviewed in this report. However, applying PET in actual clinical situations is quite challenging due to several inherent limitations of this modality, including the availability, logistics and complexity of the technique. The standard PET technique for brain ischemia is to use ${ }^{15} \mathrm{O}$ as a radiotracer. This provides quantitative values on the perfusion $(\mathrm{CBF})$ and oxygen consumption $\left(\mathrm{CMRO}_{2}\right)$, along with information on the OEF and CBV.

The concept of "misery perfusion" is peculiar to PET: this is a possible PET equivalent of the functional ischemia/penumbra that is characterized by a reduced $\mathrm{CBF}$ and a preserved $\mathrm{CMRO}_{2}$, which fits the concept of the penumbra. The hallmark of this condition is an increased OEF ranging from the normal value $(0.3-0.4)$ to the theoretical maximum (1.0) (51). The extent of the penumbra depends on the time of the measurement relative to the onset of ischemia. In most cases, the volume of the penumbra characterized by misery perfusion is usually quite extensive within the first hour of symptom onset, and the extent of the penumbra will gradually decrease with the passage of time. However, the penumbra can be seen 16 hours (52), and even up to 48 hours, after the onset of symptoms (53).

There have been some new trials applying various radiotracers other than the ${ }^{15} \mathrm{O}$ tracers. One of these is ${ }^{11} \mathrm{C}$ flumazenil that selectively binds to the benzodiazepine site on the $\gamma$-amino-butyric acid (GABA) receptor. One study showed that ${ }^{11} \mathrm{C}$-flumazenil PET successfully distinguished irreversible damage from the penumbral tissue early after ischemic stroke (54). There are some other markers of tissue hypoxia such as the nitroimidazole derivative misonidazole. PET with ${ }^{18}$ fluoro-misonidazole $\left({ }^{18} \mathrm{~F}-\mathrm{MISO}\right)$ revealed an increased uptake surrounding a zone of absent activity, which disappeared during the chronic phase, and this might serve as an alternative method for identifying the penumbra (55). The study also found that $30 \%$ of the penumbral tissue was present even after approximately 20 hours of onset. A limitation of this method's application to acute stroke is the delay between tracer injection and the imaging that usually takes more than two hours (55).

\section{Single Photon Emission Computed Tomography}

${ }^{99 m}$ Technetium (Tc)-hexamethylpropylene-amino-oxime (HMPAO) has been the most frequently used tracer for those cerebral perfusion studies that have used SPECT, and it is now being replaced by ${ }^{99 \mathrm{~m}} \mathrm{Tc}$-ethyl-cysteinatedimer (ECD) because the latter has the additional ability of reflecting the tissue metabolic status. SPECT can demonstrate the location, size and extent of the CBF abnormality immediately after the onset of ischemia; however, the detection of the penumbra is difficult because the obtained $\mathrm{CBF}$ values are relative perfusion measures. Despite this limitation, many studies have been performed to obtain the hemodynamic threshold values and they have presented various findings (7). As a result, the tissues with a tracer uptake between $40-70 \%$ of the contralateral areas during the first 3-6 hours after stroke onset can be considered as the ischemic penumbra (7).

\section{Conclusion}

The concept of the ischemic penumbra lies in the heart of the ischemic process. Because it is the target of our therapeutic efforts, it is crucial to have a thorough knowledge of the ischemic penumbra, not only to properly understand the cerebral ischemic process, but also for interpreting and applying the findings from diverse imaging studies. Without PET, although its clinical application is limited, it was previously impossible for us to gain such valuable knowledge. When considering the medical adage, "Time is brain," the ability to swiftly and easily image the hyperacute ischemic stroke patient is an essential virtue of a technique, which can be multi-modal MR imaging or MDCT, although both these methods still have some limitations in revealing the penumbra. More research is mandatory to resolve these problems.

\section{References}

1. Tissue plasminogen activator for acute ischemic stroke. The National Institute of Neurological Disorders and Stroke rt-PA Stroke Study Group. N Engl J Med 1995;333:1581-1587

2. Furlan A, Higashida R, Wechsler L, Gent M, Rowley H, Kase C, 


\section{Imaging of Ischemic Penumbra in Acute Stroke}

et al. Intra-arterial prourokinase for acute ischemic stroke. The PROACT II study: a randomized controlled trial. Prolyse in Acute Cerebral Thromboembolism. JAMA 1999;282:2003-2011

3. Baron JC. Mapping the ischemic penumbra with PET: a new approach. Brain 2001;124:2-4

4. Astrup J, Siesjo BK, Symon L. Thresholds in cerebral ischemia the ischemic penumbra. Stroke 1981;12:723-725

5. Astrup J, Symon L, Branston NM, Lassen NA. Cortical evoked potential and extracellular $\mathrm{K}^{+}$and $\mathrm{H}^{+}$at critical levels of brain ischemia. Stroke 1977;8:51-57

6. Baron JC. Positron Emission Tomography. In: Barnett H, Mohr JP, Stein BM, Yatsh FM, eds. Stroke: Pathophysiology, Diagnosis, and Management. Philadelphia: Churchill Livingstone, 1998:101-119

7. Heiss WD. Ischemic penumbra: evidence from functional imaging in man. J Cereb Blood Flow Metab 2000;20:1276-1293

8. Firlik AD, Rubin G, Yonas H, Wechsler LR. Relation between cerebral blood flow and neurologic deficit resolution in acute ischemic stroke. Neurology 1998;51:177-182

9. Schlaug G, Benfield A, Baird AE, Siewert B, Lovblad KO, Parker RA, et al. The ischemic penumbra: operationally defined by diffusion and perfusion MRI. Neurology 1999;53:1528-1537

10. Powers WJ. Cerebral hemodynamics in ischemic cerebrovascular disease. Ann Neurol 1991;29:231-240

11. Sharp FR, Swanson RA, Honkaniemi J, Kogure K, Massa SM. Neurochemistry and Molecular Biology. In: Barnett H, Mohr JP, Stein BM, Yatsh FM, eds. Stroke: Pathophysiology, Diagnosis, and Management. Philadelphia: Churchill Livingstone, 1998:51-83

12. Read SJ, Hirano T, Abbott DF, Markus R, Sachinidis JI, TochonDanguy HJ, et al. The fate of hypoxic tissue on 18Ffluoromisonidazole positron emission tomography after ischemic stroke. Ann Neurol 2000;48:228-235

13. Warach S. Tissue viability thresholds in acute stroke: the 4factor model. Stroke 2001;32:2460-2461

14. Tomandl BF, Klotz E, Handschu R, Stemper B, Reinhardt F, Huk WJ, et al. Comprehensive imaging of ischemic stroke with multisection CT. Radiographics 2003;23:565-592

15. von Kummer R, Bourquain H, Bastianello S, Bozzao L, Manelfe $\mathrm{C}$, Meier D, et al. Early prediction of irreversible brain damage after ischemic stroke at CT. Radiology 2001;219:95-100

16. Wintermark M, Bogousslavsky J. Imaging of acute ischemic brain injury: the return of computed tomography. Curr Opin Neurol 2003;16:59-63

17. Mayer TE, Hamann GF, Baranczyk J, Rosengarten B, Klotz E, Wiesmann M, et al. Dynamic CT perfusion imaging of acute stroke. AJNR Am J Neuroradiol 2000;21:1441-1449

18. Hossmann KA. Viability thresholds and the penumbra of focal ischemia. Ann Neurol 1994;36:557-565

19. Wintermark M, Reichhart M, Thiran JP, Maeder P, Chalaron M, Schnyder P, et al. Prognostic accuracy of cerebral blood flow measurement by perfusion computed tomography, at the time of emergency room admission, in acute stroke patients. Ann Neurol 2002;51:417-432

20. Yuh WT, Crain MR, Loes DJ, Greene GM, Ryals TJ, Sato Y. MR imaging of cerebral ischemia: findings in the first 24 hours. AJNR Am J Neuroradiol 1991;12:621-629

21. Bryan RN, Levy LM, Whitlow WD, Killian JM, Preziosi TJ, Rosario JA. Diagnosis of acute cerebral infarction: comparison of CT and MR imaging. AJNR Am J Neuroradiol 1991;12:611620
22. Brant-Zawadzki M, Atkinson D, Detrick M, Bradley WG, Scidmore G. Fluid-attenuated inversion recovery (FLAIR) for assessment of cerebral infarction. Initial clinical experience in 50 patients. Stroke 1996;27:1187-1191

23. Toyoda K, Ida M, Fukuda K. Fluid-attenuated inversion recovery intraarterial signal: an early sign of hyperacute cerebral ischemia. AJNR Am J Neuroradiol 2001;22:1021-1029

24. Hoehn-Berlage M, Norris DG, Kohno K, Mies G, Leibfritz D, Hossmann KA. Evolution of regional changes in apparent diffusion coefficient during focal ischemia of rat brain: the relationship of quantitative diffusion NMR imaging to reduction in cerebral blood flow and metabolic disturbances. J Cereb Blood Flow Metab 1995;15:1002-1011

25. Beauchamp NJ Jr, Ulug AM, Passe TJ, van Zijl PC. MR diffusion imaging in stroke: review and controversies. Radiographics 1998;18:1269-1283; discussion 1283-1285

26. Li F, Silva MD, Liu KF, Helmer KG, Omae T, Fenstermacher $\mathrm{JD}$, et al. Secondary decline in apparent diffusion coefficient and neurological outcomes after a short period of focal brain ischemia in rats. Ann Neurol 2000;48:236-244

27. Kidwell CS, Saver JL, Mattiello J, Starkman S, Vinuela F, Duckwiler G, et al. Thrombolytic reversal of acute human cerebral ischemic injury shown by diffusion/perfusion magnetic resonance imaging. Ann Neurol 2000;47:462-469

28. Grant PE, He J, Halpern EF, Schaefer PW, Schwamm LH, Sorensen AG, et al. Frequency and clinical context of decreased apparent diffusion coefficient reversal in the human brain. Radiology 2001;221:43-50

29. Fiehler J, Foth M, Kucinski T, Knab R, von Bezold M, Weiller $\mathrm{C}$, et al. Severe ADC decreases do not predict irreversible tissue damage in humans. Stroke 2002;33:79-86

30. Fiehler J, Knudsen K, Kucinski T, Kidwell CS, Alger JR, Thomalla G, et al. Predictors of apparent diffusion coefficient normalization in stroke patients. Stroke 2004;35:514-519

31. Hermier M, Nighoghossian N. Contribution of susceptibilityweighted imaging to acute stroke assessment. Stroke 2004;35:1989-1994

32. Warach S, Li W, Ronthal M, Edelman RR. Acute cerebral ischemia: evaluation with dynamic contrast-enhanced MR imaging and MR angiography. Radiology 1992;182:41-47

33. Maeda M, Itoh S, Ide H, Matsuda T, Kobayashi H, Kubota T, et al. Acute stroke in cats: comparison of dynamic susceptibilitycontrast MR imaging with T2- and diffusion-weighted MR imaging. Radiology 1993;189:227-232

34. Grandin CB, Duprez TP, Smith AM, Oppenheim C, Peeters A, Robert AR, et al. Which MR-derived perfusion parameters are the best predictors of infarct growth in hyperacute stroke? Comparative study between relative and quantitative measurements. Radiology 2002;223:361-370

35. Butcher K, Parsons M, Baird T, Barber A, Donnan G, Desmond $\mathrm{P}$, et al. Perfusion thresholds in acute stroke thrombolysis. Stroke 2003;34:2159-2164

36. Kim JH, Shin T, Park JH, Chung SH, Choi NC, Lim BH. Various patterns of perfusion-weighted MR imaging and MR angiographic findings in hyperacute ischemic stroke. AJNR Am J Neuroradiol 1999;20:613-620

37. Sorensen AG, Buonanno FS, Gonzalez RG, Schwamm LH, Lev $\mathrm{MH}$, Huang-Hellinger FR, et al. Hyperacute stroke: evaluation with combined multisection diffusion-weighted and hemodynamically weighted echo-planar MR imaging. Radiology 1996;199:391-401 
38. Abe O, Aoki S, Shirouzu I, Kunimatsu A, Hayashi N, Masumoto T, et al. MR imaging of ischemic penumbra. Eur J Radiol 2003;46:67-78

39. Castillo M, Kwock L, Mukherji SK. Clinical applications of proton MR spectroscopy. AJNR Am J Neuroradiol 1996;17:1-15

40. Sager TN, Laursen H, Hansen AJ. Changes in N-acetylaspartate content during focal and global brain ischemia of the rat. J Cereb Blood Flow Metab 1995;15:639-646

41. Higuchi T, Fernandez EJ, Maudsley AA, Shimizu H, Weiner MW, Weinstein PR. Mapping of lactate and N-acetyl-Laspartate predicts infarction during acute focal ischemia: in vivo $1 \mathrm{H}$ magnetic resonance spectroscopy in rats. Neurosurgery 1996;38:121-129; discussion 129-130

42. Barker PB, Gillard JH, van Zijl PC, Soher BJ, Hanley DF, Agildere AM, et al. Acute stroke: evaluation with serial proton MR spectroscopic imaging. Radiology 1994;192:723-732

43. Walker PM, Ben Salem D, Lalande A, Giroud M, Brunotte F. Time course of NAA T2 and $\mathrm{ADC}(\mathrm{w})$ in ischemic stroke patients: 1H MRS imaging and diffusion-weighted MRI. J Neurol Sci 2004;220:23-28

44. Grohn OH, Lukkarinen JA, Oja JM, van Zijl PC, Ulatowski JA, Traystman JA, et al. Noninvasive detection of cerebral hypoperfusion and reversible ischemia from reductions in the magnetic resonance imaging relaxation time, T2. J Cereb Blood Flow Metab 1998;18:911-920

45. Lee JM, Vo KD, An H, Celik A, Lee Y, Hsu CY, et al. Magnetic resonance cerebral metabolic rate of oxygen utilization in hyperacute stroke patients. Ann Neurol 2003;53:227-232

46. An H, Lin W. Quantitative measurements of cerebral blood oxygen saturation using magnetic resonance imaging. J Cereb Blood Flow Metab 2000;20:1225-1236

47. An H, Lin W, Celik A, Lee YZ. Quantitative measurements of cerebral metabolic rate of oxygen utilization using MRI: a volunteer study. NMR Biomed 2001;14:441-447

48. Roussel SA, van Bruggen N, King MD, Gadian DG.

Identification of collaterally perfused areas following focal cerebral ischemia in the rat by comparison of gradient echo and diffusion-weighted MRI. J Cereb Blood Flow Metab 1995; 15:578-586

49. Baron JC. Mapping the ischemic penumbra with PET: implications for acute stroke treatment. Cerebrovasc Dis 1999;9:193201

50. Heiss WD. Imaging the ischemic penumbra and treatment effects by PET. Keio J Med 2001;50:249-256

51. Baron JC, Bousser MG, Rey A, Guillard A, Comar D, Castaigne P. Reversal of focal "misery-perfusion syndrome" by extraintracranial arterial bypass in hemodynamic cerebral ischemia. A case study with ${ }^{15} \mathrm{O}$ positron emission tomography. Stroke 1981;12:454-459

52. Marchal G, Beaudouin V, Rioux P, de la Sayette, le Doze F, Viader F, et al. Prolonged persistence of substantial volumes of potentially viable brain tissue after stroke: a correlative PET-CT study with voxel-based data analysis. Stroke 1996;27:599-606

53. Heiss WD, Huber M, Fink GR, Herholz K, Pietrzyk U, Wagner $\mathrm{R}$, et al. Progressive derangement of periinfarct viable tissue in ischemic stroke. J Cereb Blood Flow Metab 1992;12:193-203

54. Heiss WD, Kracht L, Grond M, Rudolf J, Bauer B, Wienhard K, et al. Early $\left[{ }^{11} \mathrm{C}\right]$ Flumazenil/ $\mathrm{H}_{2} \mathrm{O}$ positron emission tomography predicts irreversible ischemic cortical damage in stroke patients receiving acute thrombolytic therapy. Stroke 2000;31:366-369

55. Read SJ, Hirano T, Abbott DF, Sachindis JI, Tochon-Danguy HJ, Chan JG, et al. Identifying hypoxic tissue after acute ischemic stroke using PET and 18F-fluoromisonidazole. Neurology 1998;51:1617-1621 